\title{
Influence of awareness of the recording of breathing on respiratory pattern in healthy humans
}

\author{
J.N. Han*, K. Stegen**, M. Cauberghs*, K.P. Van de Woestijne*
}

Influence of awareness of the recording of breathing on respiratory pattern in healthy humans. J.N. Han, K. Stegen, M. Cauberghs, K.P. Van de Woestijne. CERS Journals Ltd 1997.

ABSTRACT: This study was designed to test whether awareness of the measurement of breathing influences the breathing pattern in healthy subjects under routine laboratory conditions.

Seventy four subjects (40 females and 34 males), aged 21-63 yrs, were studied under three different conditions whilst their breathing was being recorded for $5 \mathrm{~min}$ by means of inductance plethysmography (Respitrace): 1) subjects were misled into believing that their breathing was not being recorded but that they had to wait for 5 min whilst equipment was calibrated; 2) subjects were instructed that their breathing pattern was being recorded for $5 \mathrm{~min}$; 3) the subject's breathing was recorded for $5 \mathrm{~min}$ with mouthpiece and pneumotachograph. The first two conditions were randomized. The Respitrace was calibrated by means of multiple linear regression carried out during the $5 \mathrm{~min}$ period of quiet breathing through a mouthpiece.

Awareness of the recording of breathing caused prolongation of inspiratory $(t \mathrm{I})$ and expiratory time $(t \mathrm{E})$. Breathing through the mouthpiece resulted in an increase of $t \mathrm{I}, t \mathrm{E}$ and tidal volume $(V \mathrm{~T})$. The breathing irregularities (sighs and end-expiratory pauses) decreased when subjects were aware of the recording of breathing and nearly disappeared when subjects breathed through the mouthpiece. The end-tidal carbon dioxide concentration was not significantly different between the three conditions. Mouthpiece breathing often induced some respiratory discomfort and even anxiety, particularly in females.

Awareness by the subject that his or her breathing was being recorded altered the spontaneous breathing pattern, mainly the breathing frequency. In addition, use of a mouthpiece markedly increased tidal volume, particularly in females in whom mouthpiece breathing induced more complaints than in males.

Eur Respir J., 1997; 10: 161-166.
*Laboratory of Pneumology, U.Z. Gasthuisberg, Katholieke Universiteit Leuven, Leuven, Belgium. **Dept of Psychology, University of Leuven, Leuven, Belgium.

Correspondence: K. P. Van de Woestijne Laboratory of Pneumology

U.Z. Gasthuisberg

Herestraat 49

B-3000 Leuven

Belgium

Keywords: Breathing frequency

end-tidal $\mathrm{CO}_{2}$ concentration

mouthpiece

sighs

tidal volume

Received: December 191995

Accepted after revision August 161996

Supported by the Research Council of the University of Leuven (grant OT/93/12).
It is known that in healthy subjects breathing through a mouthpiece results in an increase of tidal volume $(V \mathrm{~T})$ [1-3], of inspiratory $(t \mathrm{I})[2,3]$ and expiratory time $(t \mathrm{E})$ $[2]$, and inspiratory drive $(V \mathrm{~T} / t \mathrm{I})[2,4]$. These changes in ventilation have been attributed to: 1) the influence of the additional dead space; 2) stimulation of the nasal and oral mucosa by the noseclip and mouthpiece; 3 ) shift of respiratory route from unrestricted nose to mouth.

For these reasons, an alternative technique, i.e. respiratory inductive plethysmography (Respitrace) is widely used in the study of the breathing pattern to avoid the influence of the mouthpiece and occlusion of the nose.

As pointed out by GILBERT et al. [1], a fourth influence which might modify the natural resting ventilation is that of registration itself, by focusing the subject's attention on his breathing. The use of any recording technique, even a noninvasive one, might modify the spontaneous breathing pattern. In the present study, we tried to evaluate this influence.

\section{Materials and method}

\section{Subjects}

The study was performed on two groups of healthy volunteers: 1) 42 subjects ("younger" population), 25 females and 17 males, aged 21-26 (mean 22) yrs, who were (except for two) medical students of K.U. Leuven, Belgium; 2) 32 subjects ("older" population), 15 females and 17 males, aged 35-63 (mean 47) yrs, who were recruited from outside the hospital. All 74 subjects (younger and older population) were naive to the purpose of the study. Anonymity was ensured.

Before the experiment, the subjects answered four questionnaires. One dealt with medical history, two screened the level of anxiety, and one the spontaneous complaints of the subjects. To evaluate the anxiety of the subjects, the state and trait versions of the Zelfbeoordelingsvragenlijst (ZBV-DY1, ZBV-DY2) [5], which is the Dutch 
adapted version of the State-Trait Anxiety Inventory (STAI) of SpIELBerger et al. [6] were used. The spontaneous complaints were investigated by means of the Nijmegen Questionnaire [7]. The latter was developed as a tool to detect psychosomatic complaints. A total score of more than 23 on this questionnaire is considered to be indicative of the hyperventilation syndrome [7].

\section{Apparatus}

Breathing was recorded either with a heated pneumotachograph (Fleisch No. 2, Switzerland), lung volume being derived from electrical integration of the flow signal, or with a respiratory inductive plethysmograph (Respitrace). An infra-red $\mathrm{CO}_{2}$ monitor was connected to the mouthpiece or to the entrance of a nostril, monitoring the $\mathrm{CO}_{2}$ concentration continuously during breathing. The dead space of the pneumotachograph and mouthpiece was about $40 \mathrm{~mL}$.

\section{Calibration of Respitrace}

The Respitrace was calibrated by means of a multiple linear regression (MLR) technique [8], in the sitting position in which quiet breathing was recorded. The calibration procedure was performed during the same 5 min period of quiet breathing, during which the respiration was measured simultaneously by means of pneumotachograph and Respitrace. The breathing cycles were sampled at a rate of 20 cycles $\cdot \mathrm{s}^{-1}$. All cycles (both inspiratory and expiratory parts) were used for calibration, except for those disturbed by movement artefacts at the beginning of the recording. The output of the instruments was fed into a personal computer and stored on floppy disks, together with a time code and an identification code for subsequent analysis.

The accuracy of the MLR method for estimation of tidal volume $(V \mathrm{~T})$ was checked by comparing the $V \mathrm{~T}$ obtained simultaneously from the pneumotachograph $[9$, 10]. The data were accepted when the agreement was better than $80 \%$ for the average $V \mathrm{~T}$. Only ventilation reconstructed from Respitrace was used for further data analysis.

\section{Protocol}

The questionnaires took about $20 \mathrm{~min}$ to complete. The subjects were then seated on a comfortable chair in a quiet room. Care was taken that the subjects did not see the equipment. The coils of the Respitrace were stuck to the skin, one around the rib cage under the axilla and the other on the abdomen above the pelvis. The measurements were started as soon as the subject was connected to the equipment. Breathing was recorded under three conditions: 1) subjects were deliberately misled into believing that their breathing was not recorded but that they had to wait for 5 min for calibration of the apparatus (Condition A); 2) subjects were instructed that their breathing pattern was recorded for 5 min with Respitrace (Condition B); and 3) the subject's breathing was recorded for 5 min simultaneously with pneumotachograph (mouthpiece and noseclip) and Respitrace (Condition C). The first two conditions were randomized. The third condition was also used for the calibration of Respitrace. Before each condition, the subject was notified once "OK, I am going to record your breathing now" (Condition B) or "Please wait for 5 min without moving! The breathing is not recorded but I have to calibrate the apparatus" (Condition A) or "Please go on the mouthpiece! I am going to record your breathing now" (Condition $\mathrm{C}$ ).

Immediately after these recordings, the subjects were asked to fill in a 29 item complaint checklist, which assessed whether they experienced specific complaints during each experimental situation. The 29 items were sharp pain in the chest; a tense feeling; a feeling of looking through a mist; dizziness; a loss of contact with the surroundings; shortness of breath; a feeling of pressure or tightness in or around the chest; blown-up feeling in the belly; tingling in the fingers; not being able to breathe in fully; stiff fingers or arms; a stiff mouth; cold hands or feet; palpitations; feeling anxious; fast heart beat; an uneasy, panicky feeling; tingling in feet or legs; nausea or a tendency to throw up; feeling warm; shaking of the hands; a feeling of warmth about the head; a tightness or lump in the throat; tingling in the arms; blackness before the eyes; feeling faint; headache; tingling around the face; and a dry mouth or throat. The answers to the items of the checklist were scored as follows: $0=$ not; 1=a little; 2=clear-cut; 3=marked; 4=very marked.

\section{Data analysis}

Three periods of recording of breathing were analysed in the same manner. The reconstructed ventilation and end-tidal $\mathrm{CO}_{2}$ fraction $\left(\mathrm{FET}, \mathrm{CO}_{2}\right)$ were first plotted as a function of time to search for gross artefacts (coughs, interruptions). The latter were deleted from the data file. The reconstructed signals were then treated breath-bybreath using specially written software. After combination with $F \mathrm{ET}, \mathrm{CO}_{2}$, the following primary parameters were obtained for each breath: inspiratory time $(t \mathrm{I})$, inspiratory tidal volume $(V \mathrm{~T}, \mathrm{I})$, expiratory time $(t \mathrm{E})$, expiratory tidal volume $(V \mathrm{~T}, \mathrm{E})$, and $F \mathrm{ET}, \mathrm{CO}_{2}$. Since the mean value of $V$ T,I was not different from that of $V$ T,E, $V$ T,E was deleted from the analysis. In the present paper, $V \mathrm{~T}$ is used henceforth as a symbol for $V$ T,I.

For each period in each subject, the mean value, change of respiratory parameter as a function of time (also named slope) and residual standard deviation of the regression as a function of time (square root of mean square error $\left(\mathrm{MSE}^{1 / 2}\right)$ for each primary parameter $(t \mathrm{I}, t \mathrm{E}$, $\left.V \mathrm{~T}, F \mathrm{ET}, \mathrm{CO}_{2}\right)$ and for mean inspiratory flow rate $(V \mathrm{~T} / t \mathrm{I})$ were calculated. Slope and residual standard deviation were determined to estimate the unsteadiness of the breathing pattern and the within-subject variability of the different parameters between successive breaths. The slope variables were calculated by a linear regression over time. For the estimation of $\mathrm{MSE}^{1 / 2}$, a second degree polynomial regression was applied. If the latter was not significant at a probability level of 0.20 , a linear regression was used.

Breathing irregularities were not included for these calculations and were treated separately. Among the irregularities, two (sighs and end-expiratory pauses) occurred fairly often and were investigated. A sigh was initially 
defined as a deep breath, the volume of which exceeded three times the standard deviation of $V \mathrm{~T}$. When the breathing pattern was regular, this criterion tended to overestimate the number of sighs. Therefore, an additional criterion was also used to detect sighs: the volume should be larger than two times the average $V \mathrm{~T}$. The criteria for an end-expiratory pause were that the end-expiratory flow was less than $50 \mathrm{~mL} \cdot \mathrm{s}^{-1}$ with a duration of at least $0.5 \mathrm{~s}$. The absolute number of sighs and pauses was counted separately in the three experimental conditions.

\section{Statistical treatment}

Two-way analysis of variance (Statistical Analysis System (SAS) general linear models (GLM) procedure) providing within-subject comparisons and Duncan grouping was used to identify significant effects of the interventions on breathing variables (mean, slope and $\mathrm{MSE}^{1 / 2}$ ). Analysis of variance (ANOVA) for repeated measurements (GLM procedure with repeated statement) was performed on mean values of $t \mathrm{I}, t \mathrm{E}, V \mathrm{~T}$, and $F \mathrm{ET}, \mathrm{CO}_{2}$ to evaluate the influence of sex and age. The same type of analysis was used to identify significant effects of the interventions on complaints. The Chi-squared test was employed to compare the difference in frequency of complaints between males and females in the same intervention. The binomial distribution test was used instead of the Chi-squared test when the number of observations in the contingency tables was less than five.

\section{Results}

Biological characteristics, levels of anxiety and scores of psychosomatic complaints (Nijmegen Questionnaire) are shown in table 1 . For both state and trait anxiety the scores were those expected in a healthy population (mean of deciles: 4.5 and 4.7 for state and trait anxiety, respectively; the expected value being 5). A score of more than 23 on the Nijmegen Questionnaire was reached in only three subjects ( 2 females). The latter did not present any further evidence for the hyperventilation syndrome or for an anxiety disorder. On the basis of these results, the investigated population seemed to score normally in terms of anxiety level and presence of somatic and psychological complaints.

The ANOVA showed that, in addition to the changes of the respiratory variables and complaints resulting from the interventions, sex and age also influenced the data. Sex and sex $\times$ interventions had no statistically significant influence on $t \mathrm{I}, t \mathrm{E}$ and $V \mathrm{~T}$, but had on $F \mathrm{ET}, \mathrm{CO}_{2}$. Sex appeared primarily as a main effect on the mean value of $F \mathrm{ET}, \mathrm{CO}_{2}$, the latter being significantly less in females (5.03 vs $5.43 \%$; $<<0.0001)$. The interaction of age $\times$ interventions was significant for $t \mathrm{I}$. Accordingly,

Table 1. - Biological characteristics and level of anxiety (STAI) and number of complaints

\begin{tabular}{llllcccc}
\hline Group & $\mathrm{n}$ & $\begin{array}{l}\text { Sex } \\
\mathrm{M} / \mathrm{F}\end{array}$ & $\begin{array}{c}\text { Age* } \\
\text { yrs }\end{array}$ & $\begin{array}{c}\text { Height } \\
\mathrm{cm}\end{array}$ & $\begin{array}{c}\text { STAI } \\
\text { state }^{\#}\end{array}$ & $\begin{array}{c}\text { STAI } \\
\text { trait }^{\#}\end{array}$ & $\begin{array}{c}\text { Nijmegen } \\
\text { Questionnaire }^{\#}\end{array}$ \\
\hline All & 74 & $34 / 40$ & $33(21-63)$ & $172 \pm 10$ & $33.9 \pm 10.4$ & $35.8 \pm 10.5$ & $9.9 \pm 6.2$ \\
Young & 42 & $17 / 25$ & $22(21-26)$ & $173 \pm 10$ & $31.9 \pm 8.7$ & $33.4 \pm 8.8$ & $9.6 \pm 5.9$ \\
Old & 32 & $17 / 15$ & $47(35-63)$ & $170 \pm 8$ & $36.7 \pm 11.8$ & $39.1 \pm 11.7$ & $10.3 \pm 6.7$ \\
\hline
\end{tabular}

*: values are presented as mean, and range in parenthesis; \#: values are presented as mean \pm SD. M: male; F: female; STAI: StateTrait Anxiety Inventory.

Table 2. - Breathing parameters with and without awareness of breathing and with mouthpiece

\begin{tabular}{|c|c|c|c|c|c|}
\hline $\begin{array}{l}\text { Breathing } \\
\text { parameters }\end{array}$ & $\begin{array}{c}\text { Condition A } \\
\text { Not aware }\end{array}$ & $\begin{array}{c}\text { Condition B } \\
\text { Aware }\end{array}$ & $\begin{array}{l}\text { Condition C } \\
\text { Mouthpiece }\end{array}$ & Probability & $\begin{array}{c}\text { Duncan } \\
\text { test }\end{array}$ \\
\hline \multicolumn{6}{|c|}{ Mean \pm SD values } \\
\hline$t \mathrm{I} \quad \mathrm{s}$ & $1.9 \pm 0.6$ & $2.1 \pm 0.8$ & $2.2 \pm 1.2$ & $* * *$ & $\mathrm{~A}-\mathrm{B}, \mathrm{A}-\mathrm{C}, \mathrm{B}-\mathrm{C}$ \\
\hline$t \mathrm{E} \quad \mathrm{s}$ & $2.6 \pm 0.8$ & $2.8 \pm 1.0$ & $2.9 \pm 1.4$ & $* *$ & $\mathrm{~A}-\mathrm{B}, \mathrm{A}-\mathrm{C}$ \\
\hline$V \mathrm{~T} \mathrm{~mL}$ & $541.2 \pm 238.0$ & $575.1 \pm 260.2$ & $696.1 \pm 373.4$ & $* * *$ & $\mathrm{~A}-\mathrm{C}, \mathrm{B}-\mathrm{C}$ \\
\hline$V \mathrm{~T} / t \mathrm{I} \quad \mathrm{mL} \cdot \mathrm{s}^{-1}$ & $287.7 \pm 84.5$ & $275.5 \pm 83.1$ & $316.8 \pm 72.6$ & $* * *$ & $\mathrm{~A}-\mathrm{C}, \mathrm{B}-\mathrm{C}$ \\
\hline$F$ ET, $\mathrm{CO}_{2} \%$ & $5.21 \pm 0.57$ & $5.24 \pm 0.59$ & $5.19 \pm 0.71$ & & - \\
\hline \multicolumn{6}{|c|}{$\Delta$ mean/ $\Delta t$ values } \\
\hline$t \mathrm{I}$ & 0.0004 & 0.0002 & 0.0001 & & - \\
\hline$t \mathrm{E}$ & 0.0005 & -0.0002 & -0.0007 & & \\
\hline$V \mathrm{~T} \quad \mathrm{~mL} \cdot \mathrm{s}^{-1}$ & 0.014 & -0.073 & -0.320 & $* *$ & $\mathrm{~A}-\mathrm{C}, \mathrm{B}-\mathrm{C}$ \\
\hline$V \mathrm{~T} / t \mathrm{I} \quad \mathrm{mL} \cdot \mathrm{s}^{-2}$ & -0.098 & -0.065 & -0.119 & & - \\
\hline$F \mathrm{ET}, \mathrm{CO}_{2} \quad \% \cdot \mathrm{s}^{-1}$ & -0.0001 & -0.0003 & 0.0001 & & - \\
\hline \multicolumn{6}{|c|}{ MSE $^{1 / 2} \pm$ SD values } \\
\hline$t \mathrm{I} \quad \mathrm{s}$ & $0.4 \pm 0.2$ & $0.4 \pm 0.3$ & $0.4 \pm 0.2$ & & - \\
\hline$t \mathrm{E} \quad \mathrm{s}$ & $0.5 \pm 0.3$ & $0.5 \pm 0.2$ & $0.4 \pm 0.3$ & $*$ & $\mathrm{~A}-\mathrm{C}$ \\
\hline$V \mathrm{~T} \mathrm{~mL}$ & $116.8 \pm 83.6$ & $111.3 \pm 76.1$ & $114.1 \pm 63.8$ & & - \\
\hline$V \mathrm{~T} / t \mathrm{I} \quad \mathrm{mL} \cdot \mathrm{s}^{-1}$ & $64.7 \pm 33.0$ & $56.7 \pm 25.7$ & $60.3 \pm 19.3$ & & - \\
\hline$F$ ET, $\mathrm{CO}_{2} \%$ & $0.16 \pm 0.05$ & $0.14 \pm 0.04$ & $0.16 \pm 0.04$ & $* *$ & $\mathrm{~A}-\mathrm{B}, \mathrm{B}-\mathrm{C}$ \\
\hline
\end{tabular}

$\Delta$ mean/ $\Delta t$ : change of respiratory parameters as a function of time (also named slope); MSE ${ }^{1 / 2}$ : residual standard deviation of the regression as a function of time (square root of mean square error); $t$ I: inspiratory time; $t$ E: expiratory time; $V \mathrm{~T}$ : tidal volume; $V \mathrm{~T} / t$ I: mean inspiratory flow rate; $F \mathrm{ET}, \mathrm{CO}_{2}$ : end-tidal $\mathrm{CO}_{2}$ fraction; A: unaware of recording; B: aware of recording; C: breathing through mouthpiece. *: $\mathrm{p}<0.05$; **: $\mathrm{p}<0.01$; ***: $\mathrm{p}<0.001$. Duncan test: A-B, A-C and B-C indicate significant differences between Conditions $\mathrm{A}, \mathrm{B}$ and $\mathrm{C}$. 

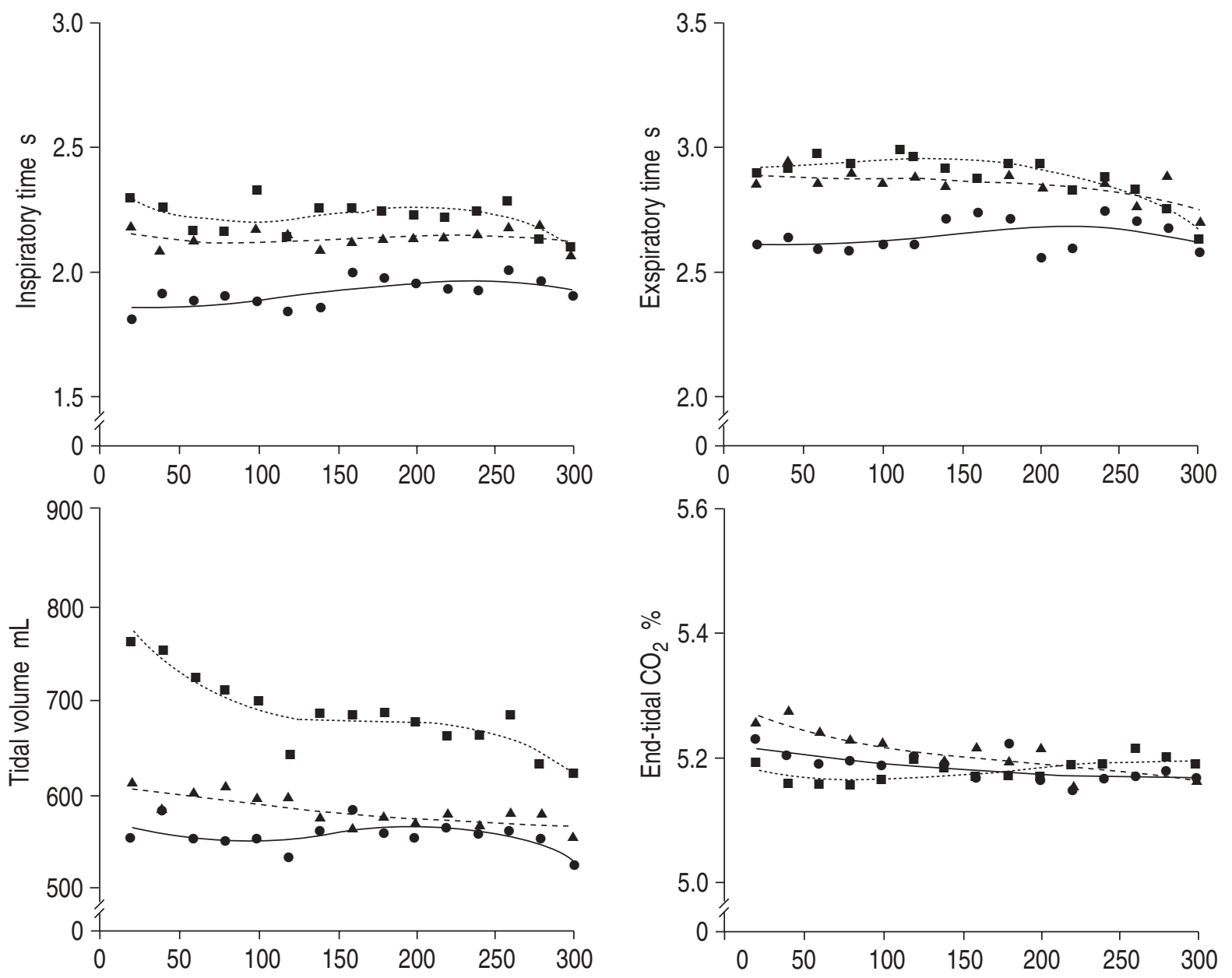

Time $s$

Fig. 1. - Time course of inspiratory and expiratory time, tidal volume and end-tidal $\mathrm{CO}_{2}$ fraction in 74 healthy subjects during 5 min breathing via mouthpiece ( $\square$; Condition C), 5 min with Respitrace aware of the recording of breathing ( $\mathbf{\Delta}$; Condition B), and 5 min with Respitrace, not aware of the recording of breathing ( $\bullet$; Condition A). Each point corresponds to the mean of a 20 s period. The lines are fitted by means of a third degree polynomial regression.

Condition A (not aware with Respitrace) was compared to Condition B (aware with Respitrace), and Condition A to $\mathrm{C}$ (mouthpiece), separately in young and old people. When these two age groups were considered separately, the interactions with age for $t$ I disappeared. Concerning the complaints, the interaction of sex $\times$ interventions was significant for respiratory complaints. We therefore separated males and females.

\section{Influence of mouthpiece}

Whilst breathing via a mouthpiece (table 2), $V \mathrm{~T} / t \mathrm{I}$ increased, compared with breathing with Respitrace both for Conditions A and B. This increase resulted mainly from a rise of $V \mathrm{~T}$, most pronounced at the start of the registration (fig. 1). With a mouthpiece, $t \mathrm{I}$ was prolonged, compared with Conditions $\mathrm{A}$ and $\mathrm{B}$; and $t \mathrm{E}$ was increased, compared to Condition A. Breathing frequency (the inverse of the sum of $t \mathrm{I}$ and $t \mathrm{E}$ ) was decreased compared to Condition A (13.1 \pm 4.0 vs $14.2 \pm 3.3$ breaths $\cdot \mathrm{min}^{-1}$; $\mathrm{p}=0.0001$ ). Minute ventilation ( $V \mathrm{~T}$ times frequency) was markedly increased, compared to Conditions A and B $\left(8.08 \pm 2.12\right.$ vs $7.03 \pm 2.04$ and $6.88 \pm 2.17 \mathrm{~L} \cdot \mathrm{min}^{-1}$, respec- tively; $\mathrm{p}=0.0001) . F \mathrm{ET}, \mathrm{CO}_{2}$ remained the same as breathing with Respitrace. Sighs and end-expiratory pauses were less frequent, compared with Condition A (table 3).

\section{Influence of self-awareness on breathing}

Self-awareness of the registration of breathing caused prolongation of both $t \mathrm{I}$ and $t \mathrm{E}, V \mathrm{~T}$ being similar both in Conditions $\mathrm{A}$ and $\mathrm{B}$. As a consequence, breathing frequency decreased $(13.2 \pm 3.4$ in $\mathrm{B}$ vs $14.2 \pm 3.3$ in $\mathrm{A}$; $\mathrm{p}=$ $0.0001)$. Minute ventilation was not significantly modified. The within-subject variability of $F \mathrm{ET}, \mathrm{CO}_{2}\left(\mathrm{MSE}^{1 / 2}\right.$ of $F \mathrm{ET}, \mathrm{CO}_{2}$ ) decreased in Condition B (table 2). Sighs and end-expiratory pauses tended to be less frequent (table 3 ).

The evolution with time of $t \mathrm{I}, t \mathrm{E}, V \mathrm{~T}, V \mathrm{~T} / t \mathrm{I}$, and $F$ ET, $\mathrm{CO}_{2}$, expressed as a linear slope did not differ significantly from zero in the three experimental conditions, except for $V \mathrm{~T}$ during condition $\mathrm{C}$.

To evaluate the order effect on breathing pattern, subjects in which breathing was recorded in Condition B preceding A were separated from those in which breathing was recorded in Condition A preceding B. In both order groups, similar results were obtained. 
Table 3. - Numbers of irregularities in the three conditions studied: not aware, aware and mouthpiece

\begin{tabular}{llcccc}
\hline Irregularities & Group & $\begin{array}{c}\text { Condition A } \\
\text { Not aware }\end{array}$ & $\begin{array}{c}\text { Condition B } \\
\text { Aware }\end{array}$ & $\begin{array}{c}\text { Condition C } \\
\text { Mouthpiece }\end{array}$ & $\begin{array}{c}\text { Probability } \\
\text { test }\end{array}$ \\
\hline Sighs & Females & 0.65 & 0.41 & 0.27 & $* .13$ \\
& Males & 0.42 & 0.13 & 0.75 & $*$ \\
And-expiratory & Females & 2.45 & 1.73 & 0.21 & A-B A-C \\
pauses & Males & 1.59 & 0.97 & A-C \\
\hline
\end{tabular}

Numbers of irregularities are means over a 5 min period. $*: \mathrm{p}<0.05 ; * *: \mathrm{p}<0.01$. For further definitions see legend to table 2.

\section{Influence of age and sex}

The difference in $t \mathrm{I}$ between Conditions $\mathrm{A}$ and $\mathrm{B}$, and between Conditions $\mathrm{A}$ and $\mathrm{C}$, was larger $(\mathrm{p}<0.01)$ in the young than in the old population both for males and females. $V$ T tended to increase more in females than in males during mouthpiece breathing $(\mathrm{p}=0.14)$. Expressed as a relative change, $V \mathrm{~T}$ increased on average by $21 \%$ in males, and by $36 \%$ in females from Conditions A to $\mathrm{C}$.

\section{Complaints}

Whilst breathing through a mouthpiece, 15 out of 40 females and 10 out of 34 males had clear-cut complaints (a score of 2 or more) for at least one item from the 29 item complaint checklist. This was significantly more $(\mathrm{p}<$ 0.001 ) than under Conditions A and B (4 females in A and B, 2 males in A and 1 in B). The complaints specifically linked to mouthpiece breathing were respiratory complaints (not being able to breathe in fully and shortness of breath) (in 42\%; 7\% with score $\geq 2$ ), anxiety (feeling anxious, and an uneasy panicky feeling) (in 14\%; none with score $\geq 2$ ), and a dry mouth (dry mouth or throat) (in $51 \% ; 28 \%$ with score $\geq 2$ ). Although a dry mouth was equally frequent among the two sexes, respiratory complaints (score $\geq 2$ ) and a little anxiety (score 1) were reported more frequently $(\mathrm{p}<0.01)$ by females. There was no clear-cut difference in the frequency of complaints between Conditions A and B.

\section{Discussion}

Conventional recording methods (requiring a mouthpiece and noseclip) used for ventilatory measurement in human subjects are known to alter the ventilation [1-4]. The present study confirmed the previous findings that breathing through the mouthpiece and occluding the nose changed the breathing pattern. Tidal volume $(V \mathrm{~T})$ rose and respiratory frequency fell (prolongation of both inspiratory $(t \mathrm{I})$ and expiratory time $(t \mathrm{E}))$. In addition, the number of breathing irregularities (sighs and pauses) decreased markedly. One possible explanation for these changes is that the process of registration itself draws the subject's attention to his or her own breathing, because of the change of respiratory route or discomfort around mouth and nose. This discomfort should not be underestimated. In addition to the expected complaint of dry mouth, other complaints were frequently reported by most subjects, but mainly by females. More than $60 \%$ of females felt more short of breath and $20 \%$ felt uneasy or slightly anxious when breathing through the mouthpiece. The fact that these complaints were more frequent in females may be related to the tendency to a more pronounced increase in $V \mathrm{~T}$ in females during mouthpiece breathing.

The awareness that breathing is recorded may also influence the breathing pattern. This was studied previously by WESTERN and PATRICK [11] in healthy male subjects. Breathing was recorded by means of a Respitrace but the subjects were told that the recording related to electrocardiographic (ECG) monitoring. The subject, wearing headphones, was asked to listen to a tape-recorded story during $5 \mathrm{~min}$ (distraction period). He was then requested to count his breaths in groups of three, also during $5 \mathrm{~min}$ (focusing). This was followed by a second distraction period. Focusing attention on breathing resulted in a increase of $t \mathrm{I}$ and of $t \mathrm{E}$ on average by $0.4 \mathrm{~s}$, and an increase of $V \mathrm{~T}$, on average by $75 \mathrm{~mL}$ (fig. 2). $V \mathrm{~T} / t \mathrm{I}$ was not influenced. Similar results were obtained when an open mask (cut away so that the dead space was not increased) was fitted to the face. The authors stressed the fact that the distraction procedure itself may affect breathing: for instance, when SHEA et al. [12] asked their subjects to listen to a story or to read a standard text, $t \mathrm{I}, t \mathrm{E}$, and $V \mathrm{~T}$ (recorded with Respitrace) decreased slightly, as compared to a condition of relaxed awareness 
without auditory or visual inputs. The changes observed were approximately half, but in the same direction, as those between focusing and distraction in the experiments by Western and Patrick [11]. Similarly, Mador and ToBIN [13] reported that audiovisual stimulation achieved by watching television resulted in an increase of breathing frequency and a slight but insignificant decrease of $V \mathrm{~T}$ (also recorded with Respitrace) in comparison to a baseline period of resting wakefulness, the subjects lying supine with eyes closed and wearing soundproof earphones.

In the present study, although the subjects rested before the experiments, a steady state of quiet breathing was not intended: the recording started as soon as the subject was connected to the equipment and interruptions between the sequence of the three conditions were avoided. The lack of a steady state of quiet breathing is clearly shown by the higher value of $V$ T (fig. 1) and a progressive decline of $V \mathrm{~T}$ during mouthpiece breathing. Even under the conditions of the present experiments, which approximated those met routinely in a lung function laboratory when breathing is recorded, awareness of the recording of breathing clearly influenced breathing frequency. Qualitatively, the results of the present study are similar to those of the study by WESTERN and PATRICK [11]. The changes in $V \mathrm{~T}$ were smaller, however, and did not reach statistical significance. It is probable that the procedure of counting the breaths in the study by WESTERN and PATRICK [11] focused the attention of the subject on breathing more than when no specific task was given. If so, the effect of "simple" awareness of the recording of breathing (without a task) might be mainly on breathing frequency, with only minimal changes of $V \mathrm{~T}$. The changes observed in the present study appear to be influenced by age because they were more pronounced in younger people. They did not significantly modify the end-tidal $\mathrm{CO}_{2}$ level.

In conclusion, under the experimental conditions of this study, comparisons of the changes in the breathing pattern induced by awareness of the recording of breathing and by the mouthpiece suggest that slowing of breathing and increase in tidal volume observed during mouthpiece breathing are due to two different mechanisms. The influence on frequency may result from the awareness of the recording of breathing, the increase in tidal volume, accompanied by a further increase in inspiratory time, being primarily an effect of the mouthpiece breathing itself.

Marked irregularities in respiratory depth and rate with frequent sighing have been described in chronic anxiety state [14], or in hyperventilation syndrome [15]. These irregularities often decrease when breathing on a mouthpiece with the nose occluded by a clip [16]. A systematic study of the breathing pattern of patients with anxiety disorders is not available, however. We suggest that the present data, because they were obtained from healthy subjects who were not abnormally anxious and did not suffer from the hyperventilation syndrome, might provide appropriate control data for such a study.

\section{References}

1. Gilbert R, Auchincloss JH, Brodsky J, Boden W. Changes in tidal volume, frequency and ventilation induced by their measurement. J Appl Physiol 1972; 33: 252-254.

2. Perez W, Tobin MJ. Separation of factors responsible for change in breathing pattern induced by instrumentation. J Appl Physiol 1985; 59: 1515-1520.

3. Rodenstein DO, Mercenier C, Stanescu DC. Influence of the respiratory route on the resting breathing pattern in humans. Am Rev Respir Dis 1985; 131: 163-166.

4. Paek D, McCool FD. Breathing patterns during varied activities. J Appl Physiol 1992, 73: 887-893.

5. Van der Ploeg HM, Defares PB, Spielberger CD. Handleiding bij de Zelfbeoordelingsvragenlijst ZBV: een nederlandstalige bewerking van de Spielberger State-Trait Anxiety Inventory STAI-DY. Lisse, Swets \& Zeitlinger, 1979.

6. Spielberger CD, Gorsuch RL, Luchene RE. The StateTrait Anxiety Inventory (STAI) test manual for form X. Palo Alto, CA, Consulting Psychologist Press, 1970.

7. Van Dixhoorn J, Duivenvoorden HJ. Efficacy of Nijmegen Questionnaire in recognition of the hyperventilation syndrome. J Psychosom Res 1985; 29: 199-206.

8. Strömberg NOT, Dahlbäck GO, Gustafsson PM. Evaluation of various models for respiratory inductance plethysmography calibration. J Appl Physiol 1993; 74: 1206-1211.

9. Konno K, Mead J. Measurement of the separate volume changes of rib cage and abdomen during breathing. $J$ Appl Physiol 1967; 22: 407-422.

10. Watson HL, Poole DA, Sackner MA. Accuracy of respiratory inductive plethysmographic cross-sectional areas. J Appl Physiol 1988; 65: 306-308.

11. Western PJ, Patrick JM. Effects of focusing attention on breathing with and without apparatus on the face. Respir Physiol 1988, 72: 123-130.

12. Shea SA, Walter J, Pelley C, Murphy K, Guz A. The effect of visual and auditory stimuli upon resting ventilation in man. Respir Physiol 1987; 68: 345-357.

13. Mador MJ, Tobin MJ. Effect of alterations in mental activity on the breathing pattern in healthy subjects. $A m$ Rev Respir Dis 1991, 144: 481-487.

14. Christie RV. Some types of respiration in the neuroses. Q J Med 1935; 4: 427-434.

15. Lum LC. Hyperventilation: the tip and the iceberg. $J$ Psychosom Res 1975, 19: 375-383.

16. Tobin MJ, Chadha TS, Jenouri G, Birch SJ, Gazeroglu HB, Sackner MA. Breathing patterns. 2. Diseased subjects. Chest 1983, 84: 286-294. 